\title{
Sobre martírios e curas: medicina e edificação nas reduções jesuítico-guaranis (século XVII)
}

\author{
ELIANE CRISTINA DECKMANN FLECK*
}

Resumo: Este artigo aborda o envolvimento dos missionários jesuítas com o atendimento de indígenas enfermos, entendido como prática que confere sentido e relevância ao apostolado e através da qual alcançam sua edificação pela salvação das almas dos indígenas. $\mathrm{O}$ empenho pela cura das enfermidades que comprometiam o alcance deste objetivo fica evidenciado na utilização da farmacopéia e das práticas terapêuticas americanas, apesar da negação de sua eficácia ritual tradicional.

\begin{abstract}
This article broaches the involvement of the Jesuit missionaries with the attendance of ill Indians, understood as practice that confers sense and relevance to apostolate and through which they can reach their edification by salvation of the Indian souls. The effort to cure the illnesses, that compromised the reach of this objective, stays evinced in the use of the American pharmacopeia and therapeutic practices, in spite of the denial of their traditional ceremonial effectiveness.
\end{abstract}

Palavras-chave: Jesuítas. Medicina. Farmacopéia.

Key words: Jesuits. Medicine. Pharmacopeia.

\section{A vocação de servir}

O fundador da Companhia de Jesus, Inácio de Loyola, ${ }^{1} \mathrm{im}-$ primiu à escolha dos membros da Companhia e ao ingresso de jovens nos colégios um cuidado todo especial. Para isso, as Constituições alongam-se na determinação de quem podia e quem não podia ser jesuíta. Segundo Loyola, somente seriam admiti-

* A autora é Doutora em História pela PUCRS, Porto Alegre, Brasil, e Professora da Graduação e da Pós-Graduação em História da UNISINOS, São Leopoldo, Brasil.

1 Inácio de Loyola nasceu em uma família espanhola nobre em 1491. Fez carreira militar, interrompida no cerco de Pamplona, em 1521. Após uma peregrinação para Roma e Jerusalém, empreendeu estudos em Barcelona, Alcalá e Salamanca, finalizando-os em Paris, onde, juntamente com outros companheiros, fez os votos da Companhia em 1534, tendo-a dirigido até sua morte em 1516.

Estudos Ibero-Americanos. PUCRS, v. XXXI, n. 1, p. 35-50, junho 2005 
dos aqueles "cuja vida, por longas e cuidadosas provas, for bem conhecida e aprovada pelo Superior Geral" (Loyola, 1975, p. 175).

Na verdade, o intento de Inácio de Loyola era o de admitir pessoas capazes de reproduzir a sua experiência pessoal e de se identificar com sua concepção de prática apostólica, condições que considerava essenciais para a dilatação do Evangelho para maior glória de Deus.²

Ele acreditava ainda que todos os dons humanos que pudessem ser válidos para esse fim, tinham de ser aproveitados, uma vez que o "homem foi criado para bendizer, fazer reverência e servir a Deus Nosso Senhor e, mediante isso, salvar sua alma" (Loyola, 1975, p. 34). Para alcançar a salvação da alma, os valores sensíveis e voluntários deveriam ser dominados e o "chamamento de Cristo Rei, que [...] convoca ao combate contra as potências de Satanás, sob o estandarte da Cruz" deveria ser aceito (Bangert, 1985, p. 20).

A vocação de servir, idealizada por Loyola, foi transformada então, na idéia de missão, que passou a moldar indiscutivelmente o pensamento e a prática da Companhia de Jesus. Destacando o caráter apostólico que Inácio pretendia imprimir, ficou estabelecido que "[...] o fim desta Companhia é não somente ocupar-se da salvação e perfeição das almas próprias com a graça divina, mas também com a mesma, procurar intensamente, ajudar à salvação e perfeição dos próximos" (Loyola, 1975, p. 307).

É importante observar ainda que para Loyola o ideal de santidade tem uma maior significação do que a ciência ou outros dons humanos, o que fica visível na VI Parte das Constituições que determina a cada jesuíta que ame a pobreza, renunciando a tudo o que possui e toda a recompensa por serviços prestados.

2 As dores torturantes sentidas por Inácio de Loyola, em decorrência dos ferimentos sofridos no cerco de Pamplona, são referidas como motivadoras de suas meditações e resoluções espirituais durante a convalescença, fornecendo um modelo de conduta pautada pela paciência e fé devota que ficaria regulamentado nas Constituições da Ordem. Apesar de ter sido acometido por diferentes e inconvenientes males, Loyola acreditava que a medicina não bastava para restabelecer completamente a saúde, exigindo da parte do próprio enfermo o desenvolvimento da virtude da paciência e da aceitação da vontade manifesta de Deus. Como fica evidenciado na biografia de Inácio de Loyola, as virtudes necessárias no momento de uma enfermidade são a obediência e a humildade, as mesmas virtudes que formam o caráter de um bom jesuíta. O envolvimento dos missionários com o atendimento aos enfermos é entendido como aquele que confere sentido e relevância à prática apostólica, desafiando as forças e o ânimo dos jesuítas e resultando na edificação através da entrega resoluta à salvação das almas. 
As Constituições esclarecem que aqueles que pretendem entrar na Companhia, "antes de começar a viver sob a obediência numa das suas residências ou colégios, devem distribuir todos os bens materiais que possuem e dispor de todos os que esperem vir a ter..." (Loyola, 1975, p. 46-47), e ainda que "se quiser seguir a Companhia, há de comer, beber, vestir-se e dormir duma maneira própria de pobres" (Loyola, 1975, p. 55). Deverá também estar "pronto e decidido a aceitar e sofrer pacientemente, com a graça de Deus, todas as injúrias, escárnios e opróbrios que andam associados às insígnias de Cristo Nosso Senhor..." (Loyola, 1975, p. 62$) \cdot{ }^{3}$

Preocupado com a formação de homens cultos, de visão católica, capazes de participar com inteligência e entusiasmo na vida civil, cultural e religiosa da sociedade, Inácio de Loyola traçou um programa de formação que visava a atender não somente à capacitação intelectual, mas também moral.

Ao definir as condições de ingresso de um postulante a membro da Companhia, Loyola estabeleceu que, embora a enfermidade do corpo devesse incitar a prática de "cosas espirituales", estes não deixassem de obedecer "con la misma humildad a los médicos corporales y enfermeros, para que gobiernen su cuerpo; pues los primeros procuran su entera salud spiritual, y los segundos toda su salud corporal" (Loyola, Constituições, apud Iparraguirre, 1952, p. 388).

Cumpre salientar que essas mesmas Constituições que interditam a formação médica aos jesuítas estabelecem que os noviços deveriam fazer estágios em um hospital durante um mês, como exercício de humildade e caridade. Além disso, previam a nomeação pelo reitor de um oficial subalterno que deveria dominar as questões relativas à conservação da saúde, do que resultaria seu crescente envolvimento no estabelecimento de farmácias e enfermarias.

É importante observar que apesar de os jesuítas terem se dedicado ao alívio dos doentes, "no les favorecía en esta matéria, ni el Derecho Canónico, ni las Constituciones de la Orden, pues, hablan estas de las ocupaciones que no convienen a clérigos y religiosos y entre ellas se cuenta la medicina, y mucho más el

3 Na biografia de Inácio de Loyola escrita por Pedro Ribadeneyra (1594), sua vida é apresentada como aquela que atualiza o exercício cristão primitivo de misericórdia e paciência, face ao sofrimento, como um espelho para o devotamento à salvação da alma. Os males do corpo são tomados, nessa perspectiva, como oportunidade para a conversão e a cura da alma. 
comercio al parecer intimamente ligado al sosten de boticas" (Leonhardt, 1937, p. 101). ${ }^{4}$ Essas proibições podiam ser, no entanto, desconsideradas, quando o atendimento se fizesse necessário, "tratandose de la misericórdia y caridad para con los pobres, cuando hace falta otro médico o cirujano" (Leonhardt, 1937, p. 103). Em 1576, o Papa Gregório XIII, outorgou à Companhia de Jesus permissão para a prática da medicina, nos seguintes termos:

Ya que consta por la experiencia, que los fieles se inclinan mucho a la religión y piedad, si las personas religiosas ejercen para con ellos los oficios de la caridad, no sólo con sus almas, sino también con sus cuerpos, y habviendo la Compañía de Jesús, según supimos, algunos religiosos entendidos en medicina, cuya asistencia ante todo en regiones donde faltan médicos, puede ser muy útil no sólo para las almas, sino también para los cuerpos, contribuyendo este oficio de caridad no poco a la edificación y a la gloria de Dios: para habilitar a semejantes religiosos a esta práctica, sin que incurran en censuras, ni se inquieten en su conciencia [...] damos este presente indulto con autoridad apostólica [...] a todos y a cada uno de la referida Compañía de Jesús, entendidos en medicina, que hay ahora o que hubiere en adelante, para que, con el permiso de sus superiores libre y lícitamente curen [...] tanto a los enfermos de la misma Religión, como a extraños y seglares con tal que no se trate de adistión o incisión hecha por ellos en persona; y en el caso de que no pueda comodamente acudir a los médicos seglares [...] (apud Leonhardt, 1937, p. 104).

Ressaltamos que, nos séculos XVI e XVII, os médicos formados nas universidades recebiam um ensino puramente acadêmico sobre os princípios de fisiologia dos humores. Aprendiam que a doença surgia de um desequilíbrio entre os quatro humores (o sangue, a fleuma, a bílis amarela e a bílis negra). O diagnóstico consistia em estabelecer qual humor estava desequilibrado, e a terapia, em medidas para recompor o equilíbrio, fosse por sangrias (com cortes na veia, escarificação ou aplicação de sanguessugas) ou submetendo o paciente a uma série de purgantes e vomitórios. Assim, o médico seguia uma monótona rotina de sangrias e purgas, prescrevendo ainda emplastros, ungüentos e poções.

4 De acordo com as Constituições: "El studio de Medicina e Leyes, como más remoto de nuestro Instituto, no se tratará en las Universidades de la Compañía, o a lo menos no tomará ella por si tal assumpto" (Loyola, Constituições apud Iparraguirre, 1952, p. 471). 


\section{A edificação pelo apostolado}

Em 1601, o Superior Geral da Cia. de Jesus decidiu reunir as regiões do Rio da Prata, Tucumã e Chile, numa Província independente, com o nome de "Paraguay", ${ }^{5}$ para a qual foram definidas diretrizes em 1609 e 1610. O 1ํㅡㄴ Concílio do Rio da Prata, realizado em Assunção, em 1603, tem, nesse contexto, uma importância fundamental, por estabelecer as metas a serem alcançadas pelos missionários, as orientações e os meios a serem empregados para "la enseñanza de la doctrina a los índios y la reforma de costumbres de los españoles" (Mateos, 1969, p. 321).

As decisões resultantes desse Concílio tornaram-se, portanto, um referencial determinante para o trabalho missionário, refletindo-se nas duas Instruções do Pe. Diego de Torres Bollo (1609 e 1610) 6 aos missionários que atuavam junto aos Guarani no Paraguai. As duas Instruções do Pe. Diego de Torres Bollo renovam as metas estabelecidas em 1603 e reforçam determinadas orientações quanto à metodologia a ser empregada pelos missionários, enfatizando a necessidade de "tirar-lhes os pecados públicos e pô-los sob policiamento", bem como de afastar os feiticeiros, por serem muito perniciosos e incitarem os índios a permanecerem em suas superstições (apud Rabuske, 1978, p. 25).

Cabe aqui referir o sétimo artigo da $1^{\text {an }}$ Instrução que deixa claras as condições que deveriam ser observadas pelos jesuítas, no momento da instalação da redução e que estão associadas à preocupação com o controle de doenças e com o eficiente abastecimento de alimentos.

$7^{\circ}$ artigo: No sítio mais apto façam a Redução e a povoação [...]. Nisso advertirão primeiro que tenha água, pescaria, boas terras e que estas não sejam todas alagadiças, nem muito quentes, mas que tenham bom clima e se apresentem sem mosquitos e isentas de outros incômodos [...] (apud Rabuske, 1978, p. 24).

5 Em 1593, ano em que a Província Jesuítica do Paraguai é desmembrada da Província do Peru, chegaram ao Paraguai quatro padres e dois irmãos coadjutores. A extensão da Província e as dificuldades encontradas para o sustento dos missionários forçaram a retirada de todos os padres do Paraguai e Tucumã, permanecendo apenas um padre em Assunção. O Pe. Diego de Torres Bollo foi enviado à Espanha em 1601, tendo retornado ao Peru, em 1607, na condição de Provincial da nova Província criada pelo Superior Geral. Para discutir as diretrizes básicas da ação a ser adotada pela Companhia na nova Província, Diego de Torres Bollo organizou, no ano seguinte, a $1^{\underline{a}}$ Congregação Provincial.

6 A primeira (1609) teve como destinatários os Padres José Cataldino e Simão Maceta, enviados ao Guairá, e a segunda (1610) foi destinada a todos os missionários jesuítas atuantes entre os indígenas do Guairá, do Paraná e entre os Guaicuru. 
Os registros feitos nas Ânuas apontam não só para a constante preocupação com os doentes (e sua potencial cura ou morte), mas também para as dificuldades encontradas pelos missionários em seu propósito de levar ajuda aos enfermos. Neste sentido, além de atuarem como médicos nas situações de epidemias, procuravam, através de medidas de prevenção, evitar a debilitação dos indígenas pela fome ou pela instalação de determinadas enfermidades.

A Carta do Pe. Lorenzo, de 6 de junho de 1610, enviada ao Pe. Diogo de Torres, ilustra as condições encontradas pelos missionários:

[...] tierra miserabilísima falta de todas las cosas. fuera de raizes de totora y pescado no ay otro regalo, los mosquitos son sin quento, ni de dia ni de noche dexan sosegar a un hombre, mis manos y cara ne las pararon tales que no parecia sino de sarnoso e leproso, certas veces me pasaba con una poco de maçamora de maiz por no haber otra cosa [...] (C. A. 1610. In: D. H. A., 1927, tomo XX, p. 65).

A falta de medicinas constitui referência constante, a exemplo da Ânua de 1613 que informa que "es grande el número de los enfermos, de los cuales dicen perece la mayor parte por falta de medicinas; además no se usa aquí la carne, ni el vacuno, por lo cual no hay nada de substancioso que pueda fortalecer los enfermos" (C. A. 1613. In: D. H. A., tomo XX, 1927, p. 294).

[...] demos desto cada dia uno de los Pes, y si es uno solo, el mismo siempre, va recoriendo todas las casas del pueblo para inquirir si ay alguno enfermo [...] (C. A. 1626-1627. In: D. H. A., Tomo XX, 1929, p. 266).

Hemos hecho algunas salidas por el Rio arriba para ver si podiamos aiudar algunos enfermos, con mucho trabajo, caminando de noche por montes arroyos i malos pasos [...] (C. A. 1626-1627. In: D. H. A., tomo XX, 1929, p. 289).

Na $1^{\text {a }}$ Instrução, destacamos o segundo artigo que refere os cuidados que os missionários deveriam ter com a sua própria saú$\mathrm{de}^{7}$, ressaltando que os mesmos deveriam acreditar na justiça e bondade divinas e confiar na proteção dos santos e anjos:

7 Na Instrução do Pe. Francisco de Borja, de março de 1567, há a explícita recomendação da observância dos cuidados necessários com a conservação da vida do missionário jesuíta, não obstante o reconhecimento da importância do martírio. 
$2^{\circ}$ artigo: Cuidarão Vossas Reverências de sua saúde e cada um pela de seu companheiro; e guardarão a devida prudência nos jejuns, vigílias e penitências, bem como em abraçar e acometer os perigos, sem faltar contudo em que for necessário na confiança que devem ter na Bondade divina e paternal Providência, e na intercessão da Soberana Virgem e dos Anjos da Guarda [...] (apud Rabuske, 1978, p. 23).

$\mathrm{Na}$ "2 $2^{\mathrm{a}}$ Instrução do Pe. Torres para todos os Missionários do Guairá, Paraná e dos Guaicurus" há recomendações que reforçam a crença na intercessão divina.

$1^{\circ}$ artigo: E que, enquanto mais cuidarmos de nossa perfeição, tanto mais nos faremos instrumentos aptos de alcançarmos a de nossos próximos, a sua salvação e a conversão dos índios, sendo que esta a havemos de negociar (conseguir) principalmente com orações contínuas, com sacrifícios e penitências (apud Rabuske, 1978, p. 30).

O desamparo, o apego às orações e o enaltecimento do martírio ficam evidenciados na Carta Ânua de 1613:

[...] el Padre Baltasar [...] muerto demasiado temprano el 19 de julio, después de solo seis años de Compañía y tres de misionero de indios. Sucumbió tan pronto por los calores excesivos de esta tierra, que le causaron una fiebre grave y desintería, habiendo el sufrido esta última y dolorosa enfermedad con edificante paciencia. Tan extrema era su penuria que siquiera se halló un mendrugo de pan para aliviarle, tanto que se puede decir con razón que su muerte fue muy semejante a la de San Francisco Javier (C. A. 1613. In: D. H. A., tomo XX, 1927, p. 464).

O valor edificante dos sofrimentos pode ser também constatado nesta passagem:

Cayó enfermo el Padre Mateo, a causa de tantos sufrimentos? ¿Qué remedio le podía proporcionar? ¿Qué alivio? Le hice una comidita más liviana, preparándole una sopita conl el afrecho de la harina de las hostias; por cierto, un banquete exquisito! Con el favor de Dios se compuso pronto (C. A. 1614. In: D. H. A., tomo XX, 1927, p. 382).

Curiosa é a crença numa "certa predestinação" dos jesuítas como médicos do corpo e da alma, o que os livraria do contágio nas epidemias.

Mientras tanto se declaró una epidemia que hizo gran estrago. [...]. El contágio se hizo tan general en la ciudad que postró también a todos los sacerdotes, menos a los de la Compañía, para que pudiesen asistir a los moribundos. No hicieron solamente esto, sino repartieron medicinas para los enfermos, y limosnas a los pobres (C. A. 1635-1637. In: D. H. A., tomo XX, 1929, p. 523). 
A dedicação incondicional dos missionários fica atestada no auxílio prestado aos enfermos do qual resultava, muitas vezes, a "morte ditosa" do jesuíta.

Acudia a todos el Pe. Graciano [...] siendo necesario muchas veces pegarse al enfermo pa poderle oir [...] sin tener su peligro ni haciendo caso se le pegaria a la peste [...] y asi andando en este exercicio [...] se sintió del mal y con calentura [...] (C. A. 1635-1637. In: D. H. A., tomo XX, 1929, p. 476-469).

[...] murió dos años y ocho meses despues de aver entrado en la Compañía [...] los últimos meses de noviciado en oficio de enfermero y lo continuó despues [...] pegosele la enfermedad en esto exercicio de que murió [...] (C. A. 1635-1637. In: D. H. A., tomo XX, 1929, p. 460).

O que pode causar estranheza é o fato de os indígenas não empregarem seus recursos de medicina no tratamento de enfermidades dos missionários, vistos como pais e protetores dos indígenas reduzidos:

[...] i a los tres dias me vi tan afligido de las llagas de los pies, no pudiendo dar paso mas adelante, los buenos Indios me llevaron otros tres dias en una hamaca [...] (C. A. 1626-1627. In: D. H. A., tomo XX, 1929, p. 310).

[...] mas con las oraziones, las oraziones del Pe. que con otro remedio, que no le avia, ni regalo ninguno [...] (C. A. 1626-1627. In: D. H. A., tomo XX, 1929, p. 294).

O Pe. Nicolas Mastrillo Duran, na Ânua de 1626, reforça o envolvimento dos missionários em atividades, "[...] que consiste, no solamente en cuydar de las almas de los indios sino tambien (y no es el menor trabajo) de sus cuerpos y de todo lo que pertenece a la industria, trato y policía humana" (C. A. 1626-1627. In: D. H. A., tomo XX, 1929, p. 264-265).

Guillermo Furlong (1962, p. 604) observa que "aunque no creemos que aquellos primeros jesuitas entendieron mucho en medicina y medicamentos, parece que a las veces, tenían efectos saludables los remedios que prescribían". O autor destaca que Roque González de Santa Cruz e Antonio Ruiz de Montoya "no eran médicos, ni entendían de medicina, sitien actuaron como curanderos en los primeros tiempos de la Reducciones", e que o Padre Altamira Santafesino "fue el primero en montar y organizar en Candelaria, la mas importante de las Reducciones, una Botica que sirviera para todas ellas". 
Vale lembrar que os missionários estavam autorizados a atender os enfermos quando constatada a falta de médico, o que determinava a instalação de enfermarias e experimentalismos com a farmacopéia à disposição. Segundo Hernández (1913, p. 16), os "misioneros recorrían las casas de los enfermos, así para llevarles los consuelos espirituales, como para ver si estaban bien asistidos, procurando que no les faltase el alimento conveniente a su estado y las medicinas posibles y a veces también haciendo de médicos y enfermeros y aun manejando la laceta por su mano". Esses aspectos ficam também evidenciados em registros feitos na Carta Ânua referente ao período de 1635 a 1637 e que informam que o Padre Ho Blas Gutierres "avia aprendido, leido y experimentado medicamentos, para acudir a los enfermos y necesitados [...] siendo juntam ${ }^{\text {te. }}$ médico y enfermero" (C. A. 1635-1637. In: D. H. A., tomo XX, 1929, p. 472-474).

Esta mesma Ânua refere o grau de envolvimento dos indígenas em atividades orientadas e desenvolvidas pelos missionários nas reduções e nos colégios: "[...] el personal que vive en el colegio, por atender a los apestados se contagian a raíz de lo cual fallecen [...]" e "[...] las indias enfermas por su parte tenían que barrer las salas [...] limpiar los instrumentos de cirujía [...]" (C. A. 1635-1637. In: D. H. A., tomo XX, 1929, p. 687).

Segundo Furlong, em cada região havia "un cuerpo de enfermeros, llamados curuzuyás, cuya misión era el enterarse cada mañana si había algún enfermo en su respectivo barrio o cuartel y como andaban los que ya se sabia que estaban enfermos". Havendo casos graves, "su primer deber era avisar de ello al Padre para que se le administrara los sacramentos [...]. El curuzuyá diagnosticaba el mal y sugería la medicina a adotarse y si contaba con la aprobación del Padre, le atendía según su saber y poder" (Furlong, 1962, p. 613).

Empenhados em atender "a todas las necesidades espirituales de aquellos pobres indios [...] sino también, [...] a las corporales" (Furlong, 1962, p. 281), os missionários que, "con más buena voluntad que ciencia adecuada, ${ }^{8}$ acudían al alivio de los enfermos" (Furlong, 1962, p. 604), aplicavam sangrias, consideradas naquela época uma panacéia contra todos os males, tão logo fosse constatada a epidemia. ${ }^{9}$

8 Segundo Echenique e Ferreira (1985, p. 251), "en materia médica los europeos no estaban más adelantados que los guaraníes", o mesmo valendo particularmente para a medicina espanhola que "no estaba muy avanzada", sendo bastante comuns os curandeiros que, valendo-se de amuletos e talismãs, "asombraban a los galenos".

9 Considerada como cura profilática, a sangria exigiu a confecção de sangradores e o recrutamento de enfermeiros, mas o próprio Padre Sepp, que enfrentou a peste de varíola em 1695, constatou não haver remédios eficazes contra este mal. 
A Décima Quarta Carta Ânua relativa aos anos de 1635 a 1637 refere a prática:

Esta peste postró en menos de ocho días a toda la población, a grandes y chicos, hombres y mujeres. Sólo yo y un joven quedamos en pie [...]. Y para cuidar a cuatro mil enfermos quedaba sólo yo com aquel joven. Aconsejáronme algunas personas, sería bueno sangrar a los dolientes, y por no haber outro cirujano, yo en persona comencé a ejercer este oficio desconocido, abriendo venas día y noche (C. A. 1635-1637. In: D. H. A., tomo XX, 1929, p. 681).

É preciso, ainda, reconhecer que "un solo médico no podía dar atención eficiente a cien mil indios, ni siquiera a la mitad" e isso pode significar "que las recetas y soluciones indígenas debían ser de uso general" (Echenique e Ferreira, 1985, p. 260), ${ }^{10}$ permitindo a sobrevivência das práticas curativas xamanísticas, bem como a receptividade às prédicas dos magos. ${ }^{11}$ Apesar de a ocasião favorecer a reavaliação e a reorganização do saber em relação à profilaxia e à terapêutica, a "medicina especial para a peste e fome" foi absorvida pelo discurso providencialista.

Acreditamos que dentre as possíveis razões para a manutenção de práticas curativas de caráter mágico esteja sua eficácia para a mudança de condutas dos indígenas e para o "cambio de sus sentimientos", já que, através delas, "tan supersticiosa gente, se trocó en cristiana y de una fe tenacisima" (C. A. 1637-1639. In: Maeder, 1984, p. 89). Buscando exatamente esse efeito - o crescente "aprovechamiento en la fe y costumbres cristianas" (C. A. 1632-1634. In: Maeder, 1990, p. 147) - os missionários mantiveram o uso de relíquias, da água benta e do sinal da cruz nas reduções.

A contestação dos xamãs - que "profieren amenazas apocalípticas" (Haubert, 1987, p. 253-254) - e sua perseguição se deveram não tanto às ervas, poções e bálsamos por eles empregados nas curas, mas à realização de milagres e à "tradicional veneración de los restos óseos de los grandes chamanes" (Haubert,

10 É oportuno lembrar que o medo e a desconfiança iniciais foram cedendo diante do "poder de cura" demonstrado pelos missionários frente às doenças desconhecidas e à ineficácia das práticas tradicionais de cura dos karaí nativos. Conforme Garlet (1997, p. 41), "não era a cura da alma ou do espírito que o demovia a aceitar o missionário, mas a cura dos males físicos".

11 Haubert (1987, p. 253-255) lembra que "los hombres-dioses se presentan através de sus atributos, como émulos o reencarnaciones de los héroes míticos de los guaraníes" e que "fundan verdaderas iglesias, instaurando cultos de una fuerza y riqueza asombrosas" que tem "su multiplicación debido a las calamidades que por todas partes los acompañan”. 
1987, p. 255), associada à pretensão de que conduziriam os índios ao Paraíso, salvando-os das enfermidades. Foram, sem dúvida, a mística envolvida nas curas xamanísticas e os rituais mágicos que garantiam a eficácia das mesmas, o que causou a oposição dos missionários. Daí, ser possível perceber o confronto entre xamãs e missionários, como uma disputa de saberes e poderes, pelo controle das doenças e pela manipulação das curas e nãocuras.

\section{A saúde das almas e dos corpos}

Na medida em que, não propriamente os recursos medicinais sofreram contestação, mas sim sua eficácia ritual, os registros feitos pelos padres jesuítas, ao longo do século XVII, revelam uma absorção cada vez maior da farmacopéia (ervas, resinas e folhas), bem como da terapêutica empregada pelos indígenas, com algumas adaptações, como nos casos dos ferimentos expostos e das otites e conjuntivites decorrentes da varíola. ${ }^{12}$ Em decorrência desses aspectos propiciadores da adaptação que a medicina e a farmacopéia das reduções jesuíticas foram consideradas das mais notáveis em seu tempo. ${ }^{13}$

A medicina presente nas reduções jesuíticas "unió al ingrediente mágico el recurso a los remedios vegetales que eran similares a los utilizados por la tradición medieval de los herbanarios monásticos,

12 "Sabemos que los indígenas utilizaban entre sus medicamientos la coca, el tabaco, y en especial la quina. Fueron los religiosos quien más hicieron por difundir sus beneficios; hasta el punto de que en la lengua inglesa la quina se conoce com el nombre de Jesuit's Bark, Jesuit's Tree, Jesuit's Powder" (Echenique e Ferreira, 1985, p. 251). A farmacopéia indígena caracteriza-se por sua "multivariedad asombrosa, y debemos citar además de la quina febrífuga, el yiquirití, las andirobas, el tabaco entre otros, la importancia que tuvo como agente terapeutico la yerba mate" (Echenique e Ferreira, 1985 , p. 257). Em relação à erva mate, destacamos seu uso medicinal pelo Irmão Pedro Montenegro: "La yerba mate tiene las cualidades del te, a las cuales añade algunas suyas propias [...] las cualidades que en ella señaló el hermano Montenegro, antigyuo enfermero jesuita de las Misiones, de servir de remedio contra las cámaras o diarrea tomada con sal, contra la relajación general de los miembros ocasionada del calor y sudor, o contra insolaciones, si se toma la infusión en agua fría; no solo tienen la confirmación que el ya alega de la experiencia de los indios [...]" (Hernández, 1913, p. 198-199).

13 "Si desde 1610 hasta 1696 no hubo en las Reducciones del Paraguay y del Uruguay médicos algunos, aunque abundaran los enfermeros, no podemos decir lo mismo por lo que respecta al siglo XVIII, ya fueron no pocos los hombres de ciencia y de experiencia técnica que dirigieron la sanidad misionera. Cada uno de los pueblos misioneros tenía sus enfermeros, pero solo había tres médicos para todos los pueblos guaraníes" (Furlong, 1962, p. 607). 
cuyo estudio había resurgido con gran vigor al comenzar el Renacimiento" (Tellez, 1993, p. 20). Por iniciativa dos missionários e boticários, foram identificadas as plantas medicinais e seus usos para incorporação no sistema médico tradicional, baseado na medicina humoral "por la cual cada medicamento tenía una cualidad, fria, cálida, seca o húmeda y un grado de exponente del uno al cuatro" (Tellez, 1993, p. 20).14

Este registro que consta da Ânua referente aos anos 1635-1637, destaca as experiências com medicamentos feitas por um jesuíta enfermeiro:

[...] porque como el havia sido enfermero tantos años y tenia tanta experiencia y notable aplicacion a su offo y com su mucha claridad avia aprendido leido y experimentado medicamentos para acudir a los enfermos y nesecitados y nro. Sr se avia comunicado acerto en el curar, los seglares teniam extraordinaria fee com sus curas esperando buen suceso en todo lo que el $\mathrm{H}^{\circ}$ Blas ponia su mano, atribuindolo a su virtud y religión [...] (C. A. 1635-1637. In: D. H. A., tomo XX, 1929, p. 472).

O experimentalismo também se revela na preocupação em encontrar as causas naturais das constantes enfermidades que se abatiam sobre as reduções. Em várias Cartas Ânuas encontramos referências a pragas de ratos, a períodos longos de fome, a calamidades climáticas que implicavam a perda da colheita, bem como aos ataques dos bandeirantes paulistas que não só causavam epidemias, mas o retorno dos indígenas aos montes e ao antigo modo de ser, para desespero dos missionários.

Cabe observar que em alguns registros os padres admitem que as doenças não decorrem, exclusivamente, da "divina justicia", mas que "a consecuencia de la transmigración y el cambio de clima aparecieron frecuentes dolencias en el pueblo", oportunidade para "experimentalismo", como na referência a que "aplicaron las medicinas del campo de aquella región, pero sin ningún resultado", e ainda para recrutar enfermeiros entre os índios sãos, "para investigar si los había [enfermos] en las casas, campos y selvas" e vigiar "contra la antigua superstición de los hechiceros" (C. A. 1637-1639. In: Maeder, 1984, p. 88).

14 "Esta patología humoral que pasó a las tierras conquistadas por España, fue curiosamente introducida, más que por médicos o boticarios, por los misioneros y el clero en general, que eran quienes en realidad asistían a los enfermos tanto en los hospitales como en los lugares más remotos, llevando a los indios además de su fe, un nuevo concepto de medicina. Los misioneros, hombres educados en las doctrinas de su tiempo, conocedores de las lenguas y la literatura clásicas y en contacto directo con el pueblo, fueron, pues, el vehículo adecuado para la difusión de la medicina homural" (Tellez, 1993, p. 22). 
As passagens abaixo ilustram o senso de observação prática dos missionários e a relação que estabeleceram entre as doenças e as condições de assentamento das populações indígenas.

[...] tierra pantanosa y llena de lagunas y mosquitos, habiendo padecido por ello muchas enfermedades [...] (apud Pastells, 1912, p. 180).

Desta peste dicen que es causa el rio porque ha crecido supra modum y fuera del curso natural con dos crecientes, que después que iba baxando ya, a su tiempo, torno a crecer outro tanto y mas, y aora esta in summo sin aber abaxado, y asi ban las enfermedades con el río. Hanse visto en el pescados disformes de grandes, sobreaguados muertos, que dicen traían la pestilencia con muchas viuoras que cogia la corriente (apud Pastells, 1912, p. 181).

Em razão disso, registraram de forma bastante detalhada o processo das doenças (o contágio, as tentativas de cura - empíricas ou exorcistas - ou então a morte), bem como as principais enfermidades (gripe, disenteria, lepra, sarampo, tifo, varíola) que se abatiam sobre os indígenas reduzidos e os colonos espanhóis instalados nos "pueblos". As passagens que transcrevemos são ilustrativas, não só da preocupação com o detalhamento da evolução das doenças, mas também revelam a percepção ocidental da doença através das imagens que constroem um "retrato de la muerte", ${ }^{15}$ bem como através da sua possível vinculação ao demônio.

Los aires del mar causaron una epidemia tan atroz que podía uno durar si tenía causas naturales o si era producida por el mismo demonio. Comenzaba la enfermedad con un intolerable dolor de cabeza. Luego torcíanse los ojos y perturbábase la razón. Extendíase el mal hacia el cuello, y quitaba la facultad de tragar y hablar. Despues salieron úlceras tan feas en la garganta, que inficionaban con su mal olor en tal grado el aliento, que el mismo enfermo parecía ahogarse entre insoportables sufrimientos. En seguida se cubría todo el cuerpo con una erupción semejante a la lepra, y en las entrañas se formaban unos gusanos peludos de asqueroso aspecto, que causaban a los enfermos agudísimos dolores. Al fin se hinchaba horriblemente

15 Estas são descrições que, sem dúvida, exploram amplamente as sensações de dor, compaixão e repugnância, através do forte apelo aos sentidos do olfato e da visão. Se as doenças são descritas com colorações tão realistas por homens experimentados e familiarizados com as epidemias na Europa, pode-se avaliar o impacto que a evolução das doenças introduzidas pelos europeus causou nos indígenas, traumatizandoos e predispondo-os a buscar a salvação da alma na conversão ao Cristianismo. 
la cara y reventaba en llagas como paperas. [...]. Adonde me volvía, no veía yo sino oscuras llagas, apostemas destilando pus y gusanos, $\mathrm{y}$ en todas partes se me presentaba el retrato de la muerte. (C. A. 1635-1637. In: D. H. A., tomo XX, 1929, p. 681).

Apesar dos sucessos obtidos através da "magia eclesiástica" e das "experiências medicinais", "los mesmos misioneros, sabían muy bien sus limitaciones y por eso se preocuparon cuanto antes, traer de Europa hombres especializados en la ciencia médica" (Furlong, apud Echenique e Ferreira, 1985, p. 258). Esta preocupação teria se materializado na solicitação de envio de médicos, enfermeiros e boticários às Missões, encaminhada ao Padre Geral da Companhia de Jesus, em 1632.

Durante o século XVII e, ainda na primeira metade do século XVIII, os jesuítas puderam exercer a medicina "y expender a la gente las necesarias medicinas", face à não existência dos chamados "Protomedicatos" que foram implantados nos diversos ViceReinos somente após a primeira metade do século XVIII. De acordo com Furlong (1962, p. 606-607) "ninguno de estos misionarios enfermos era, que sepamos, médico de profesión", o que os levou, em 1637, a solicitar ao Padre Geral da Companhia de Jesus, "cuatro hermanos que asistan en dichas Reducciones" sendo que um deles, em especial, deveria entender "algo de botica, medicina, barbería y enfermería". Essa falta de médicos é também atestada pela solicitação, feita em 1642, pelo Cabildo de Buenos Aires à cidade de Córdoba, na qual fica expresso que face a "los frecuentes apuros de peste" se faz necessária a vinda de um médico, já que "no hay médico ni medicinas" (Leonhardt, 1937, p. 110).

Em relação aos boticários existentes nos Colégios e na Reduções é ilustrativo o registro feito na Ânua de 1637-39:

Así trabajan los nuestros incansablemente en provecho de las almas, siendo al mismo tiempo muy frecuentada la portería por los pobres y hambrientos que hallan allí alivio en sus sufrimientos materiales. Se les reparte, sean pocos o sean muchos, alimentos en abundancia; no pocas veces también abrigos para cubrirse. Esto para los sanos. Para los enfermos empero, hay una botica especial en casa, de donde se reparte gratis toda clase de medicinas. Asó logra la Compañía aucir a todas las necesidades humanas, las del alma y las del cuerpo, todo por amor a Dios y por caridad para con el prójimo. [...]. Estas cosas suceden en casa. Fuera de ella no se hace menos. Continuamente son llamados los nuestros al cam- 
po y a las estancias [...] para asistir a los enfermos, tanto espiritual como corporalmente. Pues, fuera del alimento de las almas les suministran medicinas y alimentos convenientes (C. A. 1637-1639. In: Maeder, 1984, p. 33).

A descrição das atividades desenvolvidas pelos missionários revela que vivenciaram, em especial em relação às práticas terapêuticas, uma oportuna e eficiente flexibilização que lhes permitiu controlar as doenças e manipular as curas e as não-curas nas reduções. Conscientes do quanto este controle era fundamental para o êxito do projeto de civilização e de conversão da Companhia de Jesus, os missionários empenharam-se na incorporação da farmacopéia indígena, alcançando, com isso, seu maior propósito, na medida em que "buscan la salud de las almas con tanto fervor como si se tratara de salvar su propia alma" (C. A. 1637-1639. In: Maeder, 1984, p. 30) em consonância com as orientações de Inácio de Loyola.

\section{Referências}

BANGERT, W. História da Companhia de Jesus. São Paulo: Loyola, 1985.

DOCUMENTOS PARA LA HISTORIA ARGENTINA (D. H. A.). Tomos XIX e XX. Cartas Ânuas de la Provincia del Paraguay, Chile y Tucumán, de la Compañía de Jesús. v. 1 1609-1614); v. 2 (1615-1637). Buenos Aires: Talleres S. A.; Casa Jacobo Peuser, 1927; 1929.

ECHENIQUE, Nora; FERREIRA Miriam. La medicina en las reducciones jesuíticas. In: V SIMPÓSIO NACIONAL DE ESTUDOS MISSIONEIROS, 1983, Santa Rosa, RS. Anais. Santa Rosa: Faculdade de Filosofia, Ciências e Letras Dom Bosco, 1985, p. 235-252.

FURLONG, Guillermo. Misiones y sus Pueblos de Guaraníes. Buenos Aires: Teorema, 1962, p. 604.

GARLET, Ivori José. Mobilidade Mbyá: história e significação. Porto Alegre PUCRS, 1997 (Dissertação de Mestrado em História).

HAUBERT, Maxime. Indios y Jesuítas en el Paraguay. Suplemento Antropológico, v. XXII, n. 1, Asunción, Universidad Católica, Asunción, 1987.

HERNÁNDEZ S. J., Pablo. Organización social de las doctrinas guaraníes de la Compañía de Jesús. Barcelona: Gustavo Gili, 1913.

IPARRAGUIRRE, I. Obras completas de San Ignácio de Loyola. Madrid: Biblioteca de Autores Cristianos, 1952.

LEONHARDT S. J., Carlos. Los Jesuítas y la medicina en el Rio de la Plata. Estudios 57, Buenos Aires, 1937. 
LOYOLA, Inácio de. Constituições da Companhia de Jesus. Lisboa, 1975.

MAEDER, Ernesto J. A. (org.). Cartas Ânuas de la Provincia del Paraguay, 16371639. Buenos Aires: FECIC, 1984.

. (org.). Cartas Anuas de la Provincia del Paraguay, 1632-1634. Buenos Aires: FECIC, 1990.

MATEOS S. J., F. El Primer Concílio del Rio de la Plata en Asunción (1603). Missionalia Hispânica, Madrid, a. XXVI, n. 78, 1969.

PASTELLS, R. Pablo, SJ. Historia de la Compañía de Jesús en la Provincia del Paraguay. Madrid: Librería General de Victoriano Suárez, 1912.

RABUSKE, Arthur, SJ. A Carta Magna das Reduções Jesuíticas Guaranis. Estudos Leopoldenses, São Leopoldo, v. 14, n. 47, p. 21-39, 1978.

RIBADENEYRA, Pedro. Vida del P. M. Ignacio de Loyola Fundador de la Compañía de Jesús. Madrid: Pedro Madrigal, 1594.

TÉLLEZ, Carmen Sánchez. La medicina en las lenguas americanas y filipinas prehispanicas. Madrid: Publicaciones de da Universidad de Alcalá, 1993. 